\title{
Covid-19: UK needs flexible local plans to come out of lockdown, say public health experts
}

\author{
Jacqui Wise \\ London, UK
}

Local plans tailored to different parts of the UK rather than a centralised and one-size-fits-all approach are needed to mitigate the covid-19 epidemic and get the country out of lockdown, public health experts have told the government.

A letter sent to Chris Whitty, England's chief medical officer, and John Newton, the official in charge of testing, calls for local public health teams to be at the heart of the response.

Local plans would enable authorities to tailor to the "specific local and contextual factors of different parts of the UK."

Contact tracing would be achieved more easily, and cooperation would be improved between public health, social care, primary care, and hospital services.

But the letter, seen by The BMJ, says that the $£ 3.2 \mathrm{bn}(€ 3.7 \mathrm{bn}$; $\$ 4 \mathrm{bn}$ ) emergency support package for local authorities may not be enough to avoid an "uncontrolled second wave epidemic," and says more funding will be needed.

Some 22 leading public health academics and practitioners have signed the letter, including David McCoy, professor of global public health at Queen Mary University of London, and Maggie Rae, president of the Faculty of Public Health.

McCoy told The BMJ that Whitty and Newton had replied separately to the letter over the weekend and indicated they broadly agreed with the points raised. But he said, "It will not be sufficient for the government to simply decentralise responsibility to local areas. There needs to be a clear and appropriate delineation of mandates, roles, and functions."
The letter said the covid-19 response should be anchored around local authorities as they have the best understanding of the contextual factors and deprived and vulnerable groups that are key to effective and appropriate planning and implementation. They are also well placed to understand local epidemiology and monitor the impact of lockdown relaxation measures.

Primary and secondary care providers can be quickly aligned to this new organisational framework, the letter said. It also calls for the removal of unnecessary organisational barriers and for an integrated and real time information system that allows for the monitoring and support of cases, contacts, and people at risk.

McCoy said, "There will need to be a much greater role for GPs in testing, contact tracing, and monitoring of patients."

The letter said the capacity of local public health teams has been "eroded" by a combination of budget cuts and system "disorganisations" over the past decade. "While the injection of $£ 3.2 \mathrm{bn}$ to support local governments through this crisis was welcome, further efforts are needed to give local structures the resources and mandate to enable the country to release the current lockdown measures and restore the economy without risking an uncontrolled second wave epidemic," it added

McCoy added, "The capacity of local government public health teams varies considerably. Some teams could be up and running quickly, whereas others have been underfunded and would struggle." He said there should be a rapid audit so that measures can be quickly put in place to plug gaps and tackle weaknesses. 